\title{
Novo Terrorismo? Do Fracasso da GUerra AO TERror À RAdicalização VirTual
}

José Fernando Moraes Chuy

Polícia Federal e Universidade Nova de Lisboa

\begin{abstract}
RESUMO
O presente trabalho tem por objetivo estudar o "novo terrorismo", expressão que, de certa forma, acabou popularizada após o 11 de setembro, por meio de um planejado discurso político que justificou a "Guerra Global ao Terror" e que trouxe como marca a rejeição do terrorismo como crime. Buscar-se-á trazer à baila algumas consequências da priorização do recurso à força militar frente ao fenômeno, especialmente a formação de uma segunda geração de líderes terroristas por meio da radicalização virtual.
\end{abstract}

Palavras-Chave: Novo terrorismo. Discurso político. Radicalização virtual. Guerra global.

\section{INTRODUÇÃo}

A expressão "novo terrorismo" e sua efetiva existência têm gerado intensos debates entre estudiosos e especialistas. Muito mais do que semântica, a discussão se apresenta determinante para uma escorreita análise do fenômeno e ainda para uma isenta avaliação e direcionamento da prestação social protetiva estatal, conforme os ditames democráticos.

No período que de imediato sucede aos atentados desencadeados no "11 de setembro", reside o ponto nevrálgico desta pesquisa. A popularização do termo "novo terrorismo" foi impulsionada pelo fatídico e triste evento, seguindo-se uma "Guerra Global ao Terror"

Na primeira seção do trabalho busca-se identificar os motivos que levaram à classificação e ao discurso de um "novo terrorismo". Pro-

1 Nossa tradução para o termo original Global War on Terrorism - GWOT. 
cura-se abordar o campo do discurso político, tendo em vista que foi exatamente este patamar que ordenou e desencadeou significativas políticas públicas e ações antiterroristas marcadas por uma clara rejeição do terrorismo como crime.

Promovendo um recurso excessivo à força militar, que além de não produzir democracia, equilíbrio e nem tampouco estabilidade, as ações manejadas acabaram por desencadear a formação de uma segunda geração de terroristas e provocar "mais terror", largamente potencializado pela utilização das redes sociais por parte de organizações extremistas. Tal cenário será abordado na segunda seção desta pesquisa.

Ao final, buscar-se-á alinhar, analisar e relacionar os temas antes abordados, de forma a apresentar um posicionamento teórico a respeito da efetiva transformação do terrorismo contemporâneo, que permita (ou não) a sua classificação como "novo". Ademais, procurar-se-á apontar alguns caminhos para o enfrentamento moderno do fenômeno.

\section{Novo Terrorismo? O Discurso Político}

O certo é que para isso nos temos de preparar. E decerto o urgente $e ́$ - tanto programática quanto normativamente - que o façamos sem perder de vista as liberdades que tanto nos custaram a conquistar-um considerando que nem sempre, infelizmente, temos tido na devida consideração (GUEDES, 2007, p. 21).

A rotulagem "novo terrorismo" se origina no âmbito acadêmico nos anos 1990, mas o termo de fato ganha força após os atentados desencadeados nos Estados Unidos da América em 11 de setembro de 2001, quando acaba sendo de certa forma popularizado e origina a discussão do "velho terrorismo" versus o "novo terrorrismo" (GOFAS, 2012).

Autores como Peter Robert Demant (2010, p. 339-376), Walter Laqueur (1999, p. 4-7), Jonathan Stevenson (2001, v. 43, n. 4, p. 35-48), Ersun Kurtulus (2011, v. 34, p. 476-500), Joanisval Gonçalves e Marcus Vinicius Reis (2017, p. 61-62) defendem que efetivamente os atentados de 2001 seriam o marco inicial de um "novo terrorismo", perpetrado especialmente por organizações extremistas de matriz jihadista, notadamente pela Al-Qaeda e pelo Estado Islâmico. 
Essa corrente refere que "os antigos terroristas procuram negociar; novos terroristas querem apenas expressar sua ira e paralisar o inimigo" (STEVENSON, 2001, v. 43, n. 4, p. 35-48). Essa "nova onda" de ativismo terrorista seria, pois, caracterizada por motivação religiosa, estruturas organizacionais em rede, tendência a lançar ataques indiscriminados (TOMÉ, 2012) e possível uso de armas de destruição em massa. Seria diferente da anterior, tendo novos motivos, novas estruturas e novas táticas organizacionais.

Em sentido contrário, temos posicionamentos de doutrinadores como Andreas Gofas (2012, v. 8, n. 32, p. 17-32), David Tucker (2001, p. 1-14) e Martha Crenshaw (2008, p. 117-136), que observam traços de continuidade importantes entre o que seria o "antigo" e o "novo" terrorismo, tais como o foco territorial das organizações, os links transnacionais, as estruturas de rede, o fator surpresa, a provocação e a publicidade. Desta forma, não estaríamos diante de uma mudança revolucionária, mas sim de uma evolução do fenômeno, que hodiernamente apresenta uma diferença de grau, e não de espécie.

Ainda de acordo com essa corrente, o rótulo "novo" só pode ser aplicado a algo devidamente evidenciado por pesquisas históricas que de fato permitam constatar um determinado ineditismo ou uma inovadora interpretação histórica (DUYVESTEYN, 2004).

Justamente nesse ponto é que a discussão terminológica e conceitual ganha importância, dentro de uma análise que tenta identificar as razões que levaram a uma instrumentalização e a um discurso político acerca de um "novo terrorismo".

Gofas refere que justamente do "patamar político" é que resultam políticas públicas e ações. Assim, ganha importância ímpar a terminologia empregada, a forma através da qual as palavras são utilizadas. Ao classificar "retoricamente" e por meio do discurso, um problema como "novo", o campo político está passando a impressão de que as soluções apropriadas também devem trazer algo de inovador (GOFAS, 2012).

Fernandes muito bem observa que no discurso político a insegurança tem um fortíssimo potencial de exploração. O medo é utiliza- 
do como forma justificadora "para determinadas políticas de segurança e, ao mesmo tempo, servir de base a certas exigências de reforço de meios" (FERNANDES, 2012, v. II. p. 307-325).

Após observar que o terrorismo ora vivenciado é baseado em um processo histórico-evolutivo, havendo evidentes diferenças de "grau", mas não de "espécie", Crenshaw (2008, p. 120-133) constata que a formulação de "novas" políticas públicas visando securitizar a ameaça terrorista teve ancoragem justamente no campo terminológico, como forma de obtenção do "referendo" da população.

O terrorismo assim como os grupos designados terroristas são categorias que podem ser aplicadas ao discurso politico quase sem restrições, pois a legitimidade do combate ao terrorismo já está dada no plano internacional imposto pela política internacional norte-americana [...]. (SUAREZ, 2013).

Nesse aspecto, Kurtulus (observa que, na sequência do 11 de setembro consolida-se, em variados países democráticos, uma nova forma de enfrentamento ao terror.

No pós-11 de Setembro de 2001, acentuou-se a convicção de que o ambiente internacional se caracteriza pela incerteza, instabilidade, carácter difuso e perigosidade, não apenas em razão da "explosão" do terrorismo global, mas também pelo alargamento do leque de ameaças e riscos, maioritariamente originados por actores não-estatais. Inumeros Estados criaram ou reformularam os respectivos CSN, com o objectivo de melhor se adaptarem à nova realidade, por via do reajustamento dos modelos e procedimentos de segurança existentes. Os EUA, em 2002 (WHUSA, 2002); o Reino Unido (GOVUK, 2003) e a $E U$ (EU, 2003), em 2003, este último um documento colectivo e não apenas nacional; o Canadá, em 2004 (GOVCAN, 2004); a Alemanha, em 2006 (GOVGER, 2006); a Holanda (GOVNL, 2007) e a Polónia (GOVPOL, 2007), em 2007; a França (PRFRA, 2008), um documento bastante detalhado, com 350 páginas, e o Reino Unido (GOVUK, 2008) em 2008; a Finlândia (GOVFIN, 2009), o Reino Unido, (GOVUK, 2009b), a Rússia, (Schroder, 2009) e a Austrália (GOVAUS, 2009) em 2009. (FONSECA, J. 2011, p. 81-115).

A nosso ver, a Guerra Global ao Terror passa exatamente por esse aspecto. Os ataques de 2001 levaram os Estados Unidos a declarar guerra global contra o terrorismo, especificamente em face do regime Talibã, 
resultando na tentativa de destruir a Al-Qaeda por meio de uma intervenção militar no Afeganistão e, ainda, em uma guerra preemptiva em face do Iraque. Data desse período o estabelecimento do Departamento de Segurança Interna (Department of Homeland Security) e a centralização do aparato de inteligência (CRENSHAW, 2010, p. 25-26).

\subsection{A GUERRA AO TERROR: A RETÓRICA DO NOVO}

Diogo Freitas do Amaral refere a imensa dificuldade de distinção entre guerra e terrorismo, destacando que o então Presidente George Bush, em menos de 48 horas, optou por declarar que considerava como atos de guerra em face dos Estados Unidos e de todo mundo civilizado os ataques. Avaliando a referida declaração de "guerra" americana e o "USA Patriot Act", de 26 de outubro de 2001, o autor destaca:

Podemos assim concluir, para os efeitos deste estudo, que um acto de terrorismo internacional, de larga escala (provocou milhares de vitimas civis), qualificado pelo Conselho de Segurança como ameaça à paz e segurança internacionais, é na verdade um acto de guerra. Não é, pois, apenas um crime ou conjunto de crimes, regulado pelo Direito Penal, a que se responde com a policia e com os tribunais, mas um acto de guerra, regulado pelo Direito Internacional. [...]. (AMARAL, 2002, p. 765-777).

Discorrendo exatamente sobre a Lei Patriótica de 2001, Misha Glenny (2008, p. 186-188) refere que um aspecto peculiar da Guerra ao Terror era exatamente o inadequado enfrentamento às transaçóes financeiras internacionais, que acabava por confundir modelos de estratégia antiterrorismo e antilavagem de dinheiro.

Igualmente derivada do 11 de setembro, a Estratégia Nacional de Segurança de 2002 dos Estados Unidos (National Security Strategy - NSS), ${ }^{2}$ de certa forma também acaba por ser resultado do conturbado período pós-Guerra Fria, que trouxe marcante "assimetria" entre Estados consolidados frente a redes ou organizações não estatais.

A Estratégia de Segurança Nacional de 2002 reconheceu que não

2 Documento preparado periodicamente pelo poder executivo e encaminhado ao Congresso, que descreve as principais preocupações de segurança nacional dos Estados Unidos e como a administração pretende lidar com eles. Durante a gestão Bush foram editadas duas estratégias, a primeira em 2002 e a segunda em 2006. Após a gestão Bush, seguiram-se as edições sob o comando dos Presidentes Barack Obama (2010 e 2015) e de Donald Trump (2017). 
Estados são inimigos importantes e que Estados fracos são perigosos. Defendia que houvesse uma resposta dis ameaças antes que estas estivessem completamente formadas e justificou a preempção como uma autodefesa antecipada. (CRENSHAW, 2010).

Editada durante o mandato presidencial de George W. Bush, a referida Estratégia destacava que, após o colapso da União Soviética e o fim da Guerra Fria, o ambiente de segurança passou por profunda transformação e os conceitos tradicionais de dissuasão não se prestariam a enfrentar um inimigo terrorista cujas táticas declaradas são destruição e o uso de inocentes como alvo (BUSH, 2020). Por essa razão, o documento estabeleceu um verdadeiro alargamento da legítima defesa preventiva e da democratização coerciva diante das novas ameaças (MACHADO, 2013. p. 723-727).

Após o 11 de Setembro e com o status de inimigo existencial dos Estados Unidos, o terrorismo veio a ocupar o lugar que antes era privilégio da antiga União Soviética num país em que a politica externa sempre dependeu de um inimigo existencial para sua legitimação [...]. (SUAREZ, 2013)

A "Doutrina Bush" e a controversa política de guerra lançada na Estratégia Nacional de Segurança de 2002 foram objeto de severas críticas:

O documento, que tem como ponto de partida a manutenção da hegemonia americana e as responsabilidades associadas a ela, a promoção das liberdades politica e econômica imediatamente se transformou em polêmica pela introdução da possibilidade da preempção, de parte dos Estados Unidos, para lidar com ameaças potenciais. $E$ sabido que a comunidade internacional é capaz de digerir um ataque de preempção, que ocorre quando, dispondo de evidência concreta de que será aniquilado por um país $X$, o pais $Y$ se antecipa e ataca $X$. Mas, não há espaço no direito internacional para uma ação preventiva, na qual $Y$ ataca $X$ com base apenas numa suposta ameaça, intangivel e talvez meramente especulativa.

Entre preempção e prevenção existe uma barreira que é exatamente a que separa as noções da guerra justa e da guerra injusta [...]. (FROELICH, 2005, p. 205-215).

Encarar o terrorismo como uma guerra requer uma justificativa bastante robusta e específica acerca da sua efetiva necessidade. Ademais, é necessário alcançar uma legitimidade generalizada que demonstre a aceitação e a aprovação do tecido social. 
Conforme Gofas (2012), aproveitando-se da terminologia, o campo político, ao classificar "retoricamente" um problema como "novo", está passando a impressão de que as soluções apropriadas também devem trazer algo de "novo".

Ao discorrer com total propriedade acerca das funções da linguagem no viés de transformações sociais, Parker (2003) aponta que a linguagem tem condições de fazer coisas, de provocar ou mesmo de alterar o estado das coisas.

Sobre o papel central da linguagem e do discurso no enfrentamento a um suposto "novo fenômeno", Jackson (2005. p. 18) refere com precisão que "a guerra ao terrorismo é simultaneamente um conjunto de práticas - guerras, operações secretas, agências e instituições - e um conjunto de assunções, crenças, justificações e narrativas - é toda ela uma linguagem ou discurso".

De fato, a definição do terrorismo, além de envolver significativos aspectos e dilemas legais, também envolve emoção e, principalmente, muitas questões políticas (GANOR, 2005). Não por acaso, ancorada justamente no campo terminológico, e a fim de obter o necessário "aval" junto ao tecido social, decorre a formulação de "novas" políticas públicas visando securitizar a ameaça terrorista.

Kurtulus (2011, p. 37-58) destaca a transformação conceitual e qualitativa da natureza do fenômeno terrorista, que, após o 11 de setembro, deixa de ser considerado um "ato criminoso" e passa a ser enfrentado e conceituado como "ato de guerra". Tal "transformação" requer uma justificativa que lhe traga legitimidade, algo que em estados com forte formação e constituição religiosa pode ser buscado e adquirido exatamente nas bases religiosas.

Portanto, atuar "contra a guerra", diferentemente de "combater o crime", requer distinta justificação e legitimidade, daí a necessidade de uma ideologia, religiosa ou secular, com base na qual tal justificativa possa ser buscada e a legitimidade adquirida no tecido social. Kurtulus (2011, p. 37-58) pontua que, no geral, em vários discursos, pela combinação de linguagem, simbolismo religioso e ritual, o presidente Bush se referiu à "Guerra Global ao Terror" como um "chamado divino" e pelo menos em uma ocasião como uma "cruzada". 
Conforme refere Kurtulus (2011), líderes e instituições dos Estados Unidos e de Israel têm cada vez mais recorrido a metáforas religiosas e à retórica para mobilizar massas contra ameaças terroristas percebidas ou reais e, assim, justificar seu contraterrorismo.

As evidências de formulação embutida em tradicionais retóricas americanas e na vida religiosa são explicitadas por Jackson (2006, p. 163-193), aos destacar que já na década de 1980 as dicotomias de "civilização" versus "barbárie" e "bem" versus "mal", já eram notadas nos discursos de Reagan sobre terrorismo e patrocínio estatal do terrorismo.

Referido recurso a metáforas religiosas reaparece na narrativa "Guerra ao Terror" apresentada pelo governo Bush após os ataques terroristas de 11 de setembro.

\subsection{O DISCURSO MOBILIZANDO MASSAS: A HERANÇA DA GUERRA AO TERROR}

Murphy refere que o ex-Presidente Bush interpretou os ataques ocorridos no 11 de setembro da mesma forma que um "puritano" teria feito, tendo-os enquadrado como uma espécie de teste bíblico de um povo escolhido:

[...] Bush interpreted the attacks much as a Puritan would have done. They were seemingly unbelievable, but the "world He created is of moral design" (6). Why, then, did tragedies occur? The president explained that "adversity introduces us to ourselves" (6). He then recounted acts of sacrifice and courage that, in their individual parts, came together to display the whole of the nation's character in the midst of terrible trauma. "In this trial, we have been reminded," the president said [...]. (MURPHY, 2003).

$\mathrm{Na}$ mesma linha, ao abordar a possibilidade da linguagem ser criadora ou mesmo transformadora de mundos particulares de compreensão e de consensos, Silberstein afirma que, pela retórica pública, além da presidência de George Bush ser ratificada pela população, um ataque terrorista deixou de ser tratado como ato criminoso, passando a ser legitimado como um ato de guerra:

[...] about the ways language is deployed in times of national crisis. In the aftermath of the events of September 11, through public rhet- 
oric, an act of terror became a war; the Bush presidency was ratified; New York became America's city, with Rudy Giuliani as "mayor of the world". Patriotism became consumerism, dissent was discouraged, and Americans became students, newly schooled in strategic geography and Islam. Perhaps most importantly, public language (re)created a national identity (SILBERSTEIN, 2004).

Ainda seguindo o raciocínio de Kurtulus (2011), um ato criminoso demanda uma correspondente resposta da justiça criminal dentro do espaço de garantias, ao passo que o terrorismo, quando encarado como um "ato de guerra", define o fenômeno como uma atividade beligerante, uma espécie de guerra assimétrica, lançada por combatentes que podem (ou não) ser patrocinados por estados, mas que deve, no entanto, ser combatida com meios militares. Assim, de acordo com essa visão, o contraterrorismo seria mais uma questão de defesa nacional do que de ação policial. Esse paradigma beligerante aflora quando da declaração do Presidente Bush da "Guerra ao Terror" (KURTULUS, op. cit., p. 37-58).

Stevenson (2001, p. 35-48) explica que o 11 de setembro resultou na mobilização da opinião pública mais ampla contra o terrorismo de todos os tipos, tendo inclusive os americanos passado a apoiar substanciais reduções de liberdades civis como forma de reduzir as suas vulnerabilidades. Neste ponto, nos parece fundamental observar aspectos terminológicos e conceituais manejados no bojo de um processo que conduziu à instrumentalização de um discurso político que alertava a todos a respeito de um "novo terrorismo". Em tal processo foi preciso "justificar" no tecido social a necessidade de novas soluções, através de um "novo contraterrorismo".

Constata-se, pois, que o terrorismo passa a ser explorado no discurso de Bush como uma espécie de "guarda-chuva político conceitual", que permite a instrumentalização de seu enfrentamento por meio de políticas de segurança e de intervenção (SUAREZ, 2013).

Reside exatamente nesse ponto, a nosso ver, a construção premeditada e planejada de "novas" campanhas contra o terrorismo, de "novos" discursos e de "novos" projetos de violência política, os quais demandam obviamente uma série de "novas" políticas de consentimento popular dentro de uma estratégia de comunicação pública, cuidadosamente construída e perigosa. 
Em documento formalizado em outubro de 2003, Donald Rumsfeld, então Secretário de Estado dos Estados Unidos, questiona os comandantes americanos acerca dos resultados da Guerra Global ao Terror e os milionários gastos operativos estatais.

Are we capturing, killing or deterring and dissuading more terrorists every day than the madrassas and the radical clerics are recruiting, training and deploying against us? Does the US need to fashion a broad, integrated plan to stop the next generation of terrorists? The US is putting relatively little effort into a long-range plan, but we are putting a great deal of effort in trying to stop terrorists. The cost-benefit ratio is against us! Our cost is billions against the terrorists' costs of millions (EUA, 2003).

De forma semelhante, em obra que aborda o campo da estratégia militar pós 11 de setembro, John B. Alexander destaca o desenvolvimento das organizações terroristas, que passaram a ser cada vez mais audaciosas, ao passo que, em contrapartida, os Estados Unidos limitaram-se a arremessar mísseis de longa trajetória contra acampamentos suspeitos, apresentando um baixo nível de aprestamento de suas forças militares. $\mathrm{O}$ autor, Coronel da Reserva do Exército americano, critica duramente a politização e a redução da capacidade da comunidade de inteligência dos EUA, ressaltando que o 11 de setembro poderia ter sido evitado se houvesse "gente capaz de juntar as peças do quebra-cabeça” (ALEXANDER, 2005).

Criticando o uso de tecnologia e de inteligência "imprecisas" nas operações em reiteradas administrações do governo dos EUA, Kurtulus (2011 ${ }^{\text {p. } 37-58) ~ a f i r m a ~ q u e ~ a s ~ a g e ̂ n c i a s ~ d e ~ c o n t r a t e r r o r i s m o ~}$ são cada vez mais letais, causando um número desproporcionalmente alto de vítimas entre civis inocentes.

Se adentrarmos no campo dos direitos fundamentais, notaremos que a "Guerra ao Terror" utilizou-se de "velhas" formas de ataque a direitos humanos, tais como a tortura, a arbitrariedade em prisões, além de diversas violações ao devido processo legal e à integridade psicológica e física de indivíduos (HOFFMANN, 2010).

Neste aspecto específico, Gray (2016) critica fortemente a experiência norte-americana no Iraque e no Afeganistão, qualificando o fraco desempenho verificado nas referidas campanhas como decorrência de um processo político doentio, acompanhado de escolhas políticas infelizes, de uma estratégia inapropriada e de táticas inúteis. 


\subsection{O NOVO CONTRATERRORISMO NORTE-AMERICANO}

Os rumos do enfrentamento ao terrorismo por parte dos EUA após o 11 de setembro são também questionados por Joseph Nye Jr., em especial o unilateralismo de sua política externa e a estratégia excessivamente militar (hard power). A utilização da cooperação internacional e especialmente a implementação do "soft power" (poder suave) por meio da diplomacia, do apoio econômico e das comunicações, sem uso da força, seriam mais eficientes, pois permitiriam justamente a utilização da persuasão por meio de ações catalizadoras para a disseminação dos ideais americanos e da sua influência. $\mathrm{O}$ autor refere a persuasão como uma forma efetiva de poder, muito distinta do poder duro, que, além de minar a legitimidade de quem o utiliza, acaba por espalhar o receio e a desconfiança por outros países. A China é apresentada por Nye como um claro exemplo de investimento no poder suave, cuja consequência foi um significativo aumento de sua reputação internacional e uma ascensão pacífica.

Nesse sentido, cumpre trazer à baila a perfeita colocação apresentada por Kurtulus, na qual critica duramente o "novo contraterrorismo", baseado na criação de explícitos e secretos buracos negros legais distantes dos regimes de direitos humanos democráticos ("legal black holes"), na legitimação da tortura e na utilização de assassinatos extrajudiciais de terroristas suspeitos. Como retrata o autor, as táticas usadas frente ao terrorismo seriam cada vez mais letais, estando organizadas em rede e muitas vezes além do controle da soberania judicial dos tribunais.

Na primeira década do século XXI, estamos testemunhando o surgimento de uma nova forma de contraterrorismo em vários estados democráticos. Esse novo contraterrorismo é ideológico-religioso em sua perspectiva retórica, interligado em rede nas suas estruturas organizacionais, cada vez mais letal em suas táticas operacionais e cada vez mais brutal em seus métodos. A mudança para um discurso ideológico-religioso remonta a uma transformação conceitual sobre a natureza do terrorismo, da noção de terrorismo como um "crime" para a noção de uma "guerra" (KURTULUS, op. cit., p. 37-58, tradução nossa). ${ }^{3}$

3 "In the first decade of the twenty-first century we are witnessing the emergence of a new form of counterterrorism in several democratic states. This new counterterrorism is ideological-religious in its rhetorical outlook, networked in its organizational structures, increasingly lethal in its operational tactics and more and more brutal in its methods. The shift to an ideological-religious discourse can be traced back to a conceptual transformation about the nature of terrorism, from the notion of terrorism as a "crime" to that as a "war [...]". (KURTULUS, op. cit.). 
O recurso a métodos não mais aceitos em estados democráticos, notadamente a tortura em Guantánamo e em outros locais, restou por provocar grande contrariedade da opinião pública, alimentando uma perigosa generalização comunicacional que se converteu em novos recrutamentos e mobilizações de militantes radicais (GUEDES, 2007).

Patrick Cockburn (2015, p. 77), jornalista correspondente no Oriente Médio desde 1977 descreve com minúcia os acontecimentos resultantes da política externa dos Estados Unidos. Além de classificar como um" grande fracasso" a Guerra ao Terror, "em nome da qual as liberdades civis foram golpeadas e centenas de bilhões de dólares gastos, esta mesma guerra acabou por criar as melhores condições para a ascensão jihadista.

Las distintas ofensivas lanzadas por Estados Unidos y sus aliados tras el 11-S mermaron a Al Qaeda como organización, pero favorecieron su fortalecimiento como concepto: superándose la idea de estructura tradicional y constituyéndose como un conjunto de movimientos ideológicos heterogéneos. Internet y las nuevas tecnologias han supuesto un modo efectivo de explotación de este ideario salafista yihadista y propiciado que, bajo este ideario radical, diversos individuos puedan realizar actuaciones autónomas en paises occidentales sin necesidad de dependencia de una estructura de mando jerarquizada (DÍAZ MATEY, 2017, p. 207-228).

No mesmo caminho, Viola (2010, p. 91) exemplifica a situação norte-americana no Iraque, baseada em alto nível de violência, tendo culminado em devastadoras baixas nas tropas, e com o "fracassso da estratégia de confronto com o radicalismo islâmico" e com um acentuado estímulo e crescimento radicais em variadas áreas do mundo islâmico.

\section{O Terrorismo Moderno e a "Deslocalização DO TERror"}

Desde há séculos que abundam os motivos para a destruição, sob a forma dos mais diversos fanatismos, nacionalistas, ideológicos e religiosos. A diferença é que, nos dias de hoje, o mais pequeno dos grupos tem capacidade de provocar um tal tipo de danos que, antes, apenas seriam igualáveis por exércitos de estados ou por importantes movimentos revolucionários. No 
passado, para causar tais danos com eficácia, um qualquer movimento tinha que ser suficientemente amplo até almejar recrutas um apoio que lhe permitisse ganhar autoridade e capacidade de manobra. Hoje, meia duzia de pessoas pode causar mortes numa escala jamais imaginada (CARVALHO, 2016, p. 29-30).

Crucial retroceder à história do fenômeno, trazendo à baila a acurada e clássica classificação do terrorismo moderno de Rapoport, distribuída em quatro "ondas" temporais e sistemáticas, cada uma com modus operandi, objetivos e motivações distintos, as quais podem se sobrepor umas às outras, tendo duração aproximada de algumas décadas.

O terrorismo anárquico seria a primeira onda (anarchist wave), iniciando-se no Império Russo, por volta dos anos 1870 até o período pós Primeira Guerra Mundial (1920). Durante a primeira onda os anarquistas buscavam destruir a velha Rússia em suas bases, usando a estratégia de assassinatos vinculados ao regime Czarista. A segunda onda (anticolonial wave) teria início por volta de 1920 e seria representada pelo terrorismo anti-colonial na África e na Ásia, marcada pela busca pela independência de antigas colônias através de ações de guerrilha em face de forças policiais e militares. $\mathrm{O}$ terrorismo de esquerda representaria a terceira onda (new left wave), no período de 1960 a 1979, representado pela Guerra Fria e pela disputa do comunismo face ao capitalismo, marcada por tomada de aeronaves, assaltos a instituições bancárias, ataques com bombas, e ainda pela morte de centenas de civis. A quarta onda do terrorismo moderno (religious wave) resulta de significativos eventos históricos do final da década de 1970, tais como a invasão soviética ao Afeganistão, o início do novo século islâmico e a revolução iraniana. Seria a onda contemporânea, motivada por ações de cunho religioso e pela ascensão de novas organizações, com destaque para os grupos jihadistas, que redefiniram objetivos e metas com base em concepções fundamentalistas (RAPOPORT, 2004).

O surgimento de um movimento terrorista de amplitude global remonta aos anos 80 do século XIX, tendo como objetivo determinante a "eliminação pura, simples e definitiva, do poder dos Estados e do capital internacional". Os anos 90 do referido século e o início do século XX assistiram o anarquismo e o anarco-sindicalismo, sendo eles considerados pela então "Comunidade das Nações" uma ameaça 
à estabilidade internacional, contando com uma extensa lista de assassinatos. Nesse contexto, a temática acabou por dominar o cenário, resultando em uma "consolidação" de operativos policiais e, obviamente, de informações: "A Scotland Yard britânica, o FBI norte-americano, e a Okhrana russa, são três exemplos do crescimento explosivo que teve lugar." (GUEDES, 2007, P. 256-257).

Trazemos anteriormente o ensinamento de Marques Guedes (2007) relativo à passagem do século XIX para o XX, justamente para destacar sua constatação de que, no período, os anarquistas não conseguiram perfectibilizar, em âmbito mundial, uma organização ou mesmo uma conspiração em face da América ou da Europa: "Num certo sentido, a rede tecida por bin Laden ao redor da al-Qaeda logrou o que os anarquistas nunca conseguiram: alçada."

Tal "alçada" é denotada pela amplitude externa alcançada inicialmente pela Al-Qaeda ao proceder a transnacionalização do terrorismo por meio de um alargamento de ataques externos a regióes de conflito e, enormemente, graças ao proveito que soube tirar das inovações tecnológicas. Esse alcance foi ainda mais abrangente por parte do Estado Islâmico, que percebeu a utilidade da globalização, aproveitando-se da utilização de novos recursos de comunicação e das redes sociais por meio da rede mundial de computadores.

A organização soube tirar proveito do poder das redes sociais através de técnicas altamente profissionais, com robusto volume de publicações, no intuito de inundar a mídia, adaptando e desenvolvendo uma série de estratégias e de narrativas com viés de propaganda adaptada a cada tipo de público alvo (FONSECA, 2017). Percebendo que a violência bárbara atrai olhares e, ainda, gera propaganda revertida em futuros recrutamentos, o Estado Islâmico passou a se utilizar de cenas brutais muito bem editadas em filmes modernos, promovendo uma forte e alargada divulgação em diversos links e com variados tamanhos e formatos (MCCANTS, 2016).

Pode-se dizer que o ISIS se valeu do infinito da internet e operacionalizou verdadeira "terceirização midiática" tão bem enquadrada que faz com que inclusive pessoas que não são membros efetivos acabem por disseminar manifestações oficiais do grupo (crowdsourcing) (BARRET, 2014). 
Além do Estado Islâmico, é marcante a grande utilização dos meios de comunicação e das mídias sociais para divulgação, promoção, recrutamento orientação e treinamento de combatentes por parte das organizações terroristas contemporâneas (GONÇALVES, 2017).

Ao abordar os efeitos da Globalização e da Revolução da Informação, Nye Jr. prevê que neste século assistiremos a uma transição de poder entre estados e, ainda, a uma difusão de poder para as mãos de intervenientes não estatais. Destaca o autor o poder desses "bárbaros modernos", operacionalizado por meio da utilização de novas e modernas ferramentas de poder, em especial do poder da informação e da narrativa dos terroristas:

Sempre se convencionou que o estado com maior poder militar prevalece, mas na era da informação esse lugar poderá estar reservado ao estado (ou ao interveniente não estatal) com a melhor narrativa.. [...] o impacto dos terroristas depende menos do tamanho das forças do que do efeito teatral das suas ações e narrativas, e das reações excessivas que são capazes de produzir (NYE JR, 2012, p. $\left.{ }^{\text {12-1 }} 5^{\mathrm{e}} 22^{23}\right)$.

No período atual de acelerado processo de mudança, Marques Guedes (2007) registra a "deslocalização do terror", acompanhada de "intuitos políticos cada vez mais difusos", observando-se uma multiplicidade de locais de atuação. Dentro de uma simbiose entre modernidade e tradição, em um cenário assimétrico que favorece a impessoalidade e o anonimato, o terror acaba alargando suas ameças e ações.

Com tudo isso, podemos dizer que estamos a viver um momento de desterritorialização e dispersão das ameaças que põem em risco a segurança dos Estados, tornando-as imprevisiveis. O que constitui um desafio para os Estados na tomada de decisóes e na definição de estratégias que visam garantir a segurança das suas fronteiras. A tradicional divisão entre segurança interna e externa alterou-se. $O$ que nos leva a reflectir sobre o tipo de ameaças que os Estados enfrentam; quais os riscos que correm ao se relacionarem com os demais Estados e outros sujeitos do Direito internacional; a eficácia dos meios disponiveis para defesa da população e do território; e sobre a real origem das ameaças nos dias de hoje (KAJIBANGA, 2016).

$\mathrm{Na}$ moderna e complexa dinâmica de relações internacionais que atravessam fronteiras geográficas e extrapolam o controle governamental, o poder acaba por ficar na dependência do contexto, justa- 
mente por se referir a relações humanas temporárias e que se alteram constantemente (NYE JR, 2012).

A Guerra ao Terror trouxe como marca a rejeição do "terrorismo como crime" e, consequentemente, promoveu o recurso excessivo à força militar frente ao fenômeno. Esse contexto, além de não produzir uma estabilidade democrática, acabou por desencadear a formação de uma segunda geração de líderes terroristas e provocar "mais terrorismo" (CRENSHAW, 2010).

\subsection{UMA SEGUNDA GERAÇÃO DE LÍDERES TERRORISTAS}

O Estado Islâmico soube se aproveitar e "é fruto direto e indireto" da invasão norte-americana ao Iraque, que acabou por atrair milhares de jihadistas islâmicos de outros países para o Iraque (SCANDOLARA, 2017).

O terror hodierno se aproveita da avançada tecnologia da informação e de comunicação do mundo global e informatizado e ainda se vale de práticas de certa forma já antigas, combinando estas misturas que além de permitir a obtenção de recursos e a coordenação dos grupos operativos, acaba por desenvolver a difusão de propaganda política e o recrutamento de voluntários (FRAGA IRIBARNE, 2004).

O universo globalizado favorece a fluidez e a velocidade da informação, que instantaneamente é transmitida e recebida. Nesse contexto, as práticas do terror chegam imediatamente à sociedade, centralizando a atenção do público (CALLEGARI, 2016).

A internet se transformou na plataforma ideal para transmissão da mensagem da quase totalidade das organizações terroristas para uma ampla audiência. Além dos extremistas religiosos, organizações separatistas, nacionalistas, racistas e outras se aproveitam do fácil acesso à rede mundial de computadores que além de ter custo ínfimo, sofrem de falta de regulação e de controle (CARVALHO, 2016).

Napoleoni de forma muito clara observa o poder degenerativo da propaganda do terrorismo no ambiente virtual: 
Essa mutação dos efeitos da propaganda clássica causada pelas atrocidades itinerantes de organizaçôes aramadas representa uma ameaça sem igual para os paises ocidentais. Assim como os improvisados homens-bomba dos primeiros anos de 2000, os degoladores alfabetizados pelas cartilhas virtuais do faça-o-mal-você-mesmo dos dias atuais são difíceis de identificar e localizar, pois não pertencem a nenhum grupo terrorista consagrado, de vida relativamente longa, e sua radicalização nasceu da gestação de apenas alguns cliques do mouse (NAPOLEONI, 2015, p. 71).

Apenas a título quantitativo, e ainda no aspecto da promoção do terrorismo e de suas implicações Stern e Berger (2015, p.101-115) referem que as redes sociais assumem condição decisiva para a decisão de um "potencial combatente estrangeiro" e ainda nas suas ações. Estima-se que até 2014 o Estado Islâmico tenha atraído para suas "fileiras" 12.000 (doze mil) combatentes estrangeiros, sendo 2.220 (dois mil e duzentos e vinte) oriundos da Europa (sem contar aliados e simpatizantes no exterior) (AHMARI, 2014).

Documento formalizado pelo Escritório das Nações Unidas sobre Drogas e Crimes ano de 2012, intitulado "the use of internet for terrorists purposes", contabiliza nada menos do que seis objetivos buscados por organizações terroristas na rede internacional de computadores: propaganda, financiamento, treinamento, planejamento, execução e ataques cibernéticos (UNODC, 2012).

Assim, e valendo-se das "benesses" tecnológicas, os atos de terror contemporâneo apresentam robusto escopo de danos e baixo custo para as organizações que muitas vezes simplificam processos buscando dificultar a detecção pelas forças policiais (RAMOS).

Matos ainda refere que o Jihadismo global, dentro de alguns pilares teológico-doutrinários, utiliza-se enormemente da dissimulação da ação operacional, buscando preejudicar as ações preventivas de forças e de serviços de segurança. Nesse contexto, tais organizações se valem largamente da imersão e da infiltração de indivíduos (MATOS, 2019).

Nossa batalha é longa e ainda está no comę̧o. [...] eventos importantes e seus desenvolvimentos indicam a duração da batalha. Sua extensão oferece uma oportunidade para se infiltrar nos adversários e em seus companheiros de viagem $e$ 
estabelecer um forte aparato de segurança que é mais favorável à segurança do movimento agora e, mais tarde, ao Estado. Devemos infiltrar as forças policiais, os exércitos, os diferentes partidos politicos, os jornais, os grupos islâmicos, as companhias petroliferas (como funcionário ou engenheiro), companhias de segurança privada, instituições da sociedade civil, etc. Este esforço, na verdade, começou já há várias décadas, mas devemos reforçá-lo à luz dos novos acontecimentos. Da mesma forma, poderemos ter de infiltrar em um mesmo lugar mais de um membro - sem que um tenha conbecimento da existência do outro - para papéis diferentes ou um único papel, se este requerer a existência de mais do que um membro (NAJI, 2006, p.52, tradução nossa). ${ }^{4}$

Além da "alçada" atingida (GUEDES, 2007), o terrorismo passou a ser a "prima ratio" das heterogêneas organizações contemporâneas (JANUÁRIO; GAMEIRO, 2011).

Baseadas na dissimulação e na infiltração, as organizaçôes terroristas passaram a se valer da radicalização virtual a partir de motivações e de formas que acabam, em termo de ameaça sistêmica, ultrapassando fronteiras e ameaçando de forma abrangente cidadão e Estado, acarretando, assim, um significativo sentimento de insegurança e uma forte instabilidade sistêmica global.

\subsection{O CRESCENTE ATUAR DE ORGANIZAÇÕES DE OUTRAS MATRIZES}

Em decorrência do significativo volume de "jihadistas express" nascidos no próprio Ocidente e que acabam se autorradicalizando, Tomé refere que a União Europeia tem deliberado propostas que passam por essa sensível ameaça:

Entre as muitas propostas da UE, incluem-se: aprofundar o

4 "Our battle is long and still in its beginning. [...] momentous events and their developments indicate the length of the battle. Its length provides an opportunity for infiltrating the adversaries and their fellow travelers and establishing a strong security apparatus that is more supportive of the security of the movement now, and later the state. (We) should infiltrate the police forces, the armies, the different political parties, the newspapers, the Islamic groups, the petroleum companies (as an employee or as an engineer), private security companies, sensitive civil institutions, etc. That actually began several decades ago, but we need to increase it in light of recent developments. Likewise, we may need to infiltrate a single place with more than one member - one member will not know another (member) and vice versa - for different roles or the same role if it requires more than one member." (NAJI, 2006. p. 52). 
entendimento do fenómeno; apertar a vigilância das redes sociais e maior cooperação com a induistria da Internet a fim de remover conteúdos extremistas, criando contradiscursos eficazes; punir e penalizar a apologia do terrorismo e do extremismo violento, bem como a intenção de se juntar a grupos terroristas e de planear ou praticar crimes correlacionados; impedir deslocaçôes para associação a grupos terroristas, detectar e monitorizar as viagens para e desde palcos de conflitualidade jihadista e travar o regresso de extremistas e de veteranos jihadistas, designadamente com reforço dos controlos nas fronteiras externas da UE e do espaço Schengen e com registo de identificação dos passageiros [...] (TOMÉ, 2015).

Nesse aspecto é crucial trazer à baila o trabalho de Weiss e Hassan (2015, p. 153-169), formalizado após dezenas de entrevistas com elementos associados ao Estado Islâmico e que operaram na organização em variados setores. Conforme observado, o fator de atração de pessoas para o ISIS poderia igualmente levá-las a cultuar outros tipos de movimentos totalitários, inclusive ideologicamente contraditórios ao Jihadismo. Basicamente, a atração resulta de uma publicidade sofisticada, que oferece uma série de oportunidades para um segmento de pessoas, inclusive oportunistas.

Nesse cenário, Demant (2010, p. 339-376) observa que, em uma era de modernização tecnológica, de globalização e de mídia globalizada, movimentos religiosos radicais se aproveitam de oportunidades e precondições e acabam por promover a adesão de integrantes vulneráveis (em sua maioria jovens) para uma ideologia radical.

Não apenas os jovens são vulneráveis à radicalização virtual. Chama a atenção que pesquisas e doutrinadores identifiquem que, inclusive no eixo mais miserável dos países, a maioria das pessoas que migram para o terrorismo apresente alto nível educacional e diferenciada prosperidade frente aos demais membros (CRENSHAW, 2010).

O ainda recente sucesso do ISIS, que por meio dos seus "tweets" e vídeos de propaganda logrou êxito em atrair milhares de novos "recrutas" de todas partes do mundo, que queriam "se juntar à batalha antes do apocalipse final” (BECK, 2015, p. 21-27), é de certa forma um assustador "legado", que resta cristalizado. 
Nessa conjuntura, o grande risco hoje representado é o de que as organizações terroristas, de maneira geral, adaptem este legado e passem a se valer das redes sociais para maximizar seu poder ideológico e radicalizador.

Nessa direção e em termos bem atuais, constata-se a ineficácia dos métodos tradicionais de combate pela simples observação de que todo aparato bélico dos Estados Unidos e de outros paises do Ocidente não conseguiu fazer cessar os rotineiros ataques a vitimas civis, as bases americanas ou aliadas [...] esse mesmo aparato bélico é incapaz de neutralizar as ameaças quando direcionadas à população civil, como nos atentados realizados na França, Bélgica, Turquia ou Alemanha (2015 e 2016), razão pela qual ganha força a atividade de investigação de grupos e também são necessárias ações preventivas e repressivas [...] (SILVA, 2017, p.36).

Aqui concordamos plenamente com Crenshaw (2007, p.4445) no sentido de que enquanto for possível a efetivação de novos recrutamentos, o terrorismo irá persistir.

Baseadas na dissimulação e na infiltração, as organizações terroristas passaram a se valer da radicalização virtual a partir de motivações e de formas que acabam, em termo de ameaça sistêmica, ultrapassando fronteiras e ameaçando de forma abrangente cidadão e Estado, acarretando, assim, um significativo sentimento de insegurança e uma forte instabilidade sistêmica global.

\section{Conclusão}

Bem quero, mas não consigo alhear-me da comédia democrática que substituiu a comédia autocrática no palco do país. Dá vontade de chorar, ver tanta irreflexão. Não aprendemos nenhuma lição política, por mais eloquente que seja. [...] É humoralmente que elegemos, que legislamos, que governamos. E somos uma comunidade de solidões impulsivas a todos os níveis da cidadania. Com oitocentos anos de História, parecemos crianças sociais. Jogamos às escondidas nos corredores das instituições (TORGA, 2011.p. 32-33).

Chegando-se ao nível conceitual do tema, acreditamos que a concepção de uma transformação radical da atividade terrorista acarreta risco 
de simplesmente esquecer a história e o conhecimento passado, impedindo que se desenvolva uma teoria estrutural do terrorismo (GOFAS, 2012).

A presente pesquisa nos faz concluir que terrorismo não é um fenômeno novo, tendo assumido, no período contemporâneo, uma significativa mudança de contexto. As circunstâncias atuais acabam por demonstrar um terrorismo multifacetado, que, a bem da verdade, percorre todas as ondas do terrorismo moderno tão bem apresentadas por Rapoport. ${ }^{5}$

O "moderno contexto" das organizações terroristas, em certa medida (em grau) mais autônomo e espraiado, não parece ser suficientemente robusto, ou mesmo inédito. Tal quadro, a nosso ver, impossibilita que se possa considerar a existência efetiva de um "novo terrorismo".

Não nos parece correto centralizar ou mesmo limitar o terrorismo hodierno a um novo fenômeno de matriz jihadista, na medida em que, infelizmente, observa-se o crescente atuar de organizações de outras matrizes que não a religiosa, tais como a anarquista, independentista, de extrema esquerda e de extrema direita. Se admitirmos a existência de um "novo terrorismo", o que fazemos tão somente pelo sabor do argumento, de que forma classificaríamos as recentes ações terroristas de vertentes diversas da religiosa? Seriam elas uma sequela de um "velho" terror, ao passo que apenas as ações perpetradas por organizações terroristas jihadistas seriam o "novo"?

Parece-nos inexistirem fundamentos robustos que permitam concluir-se pela terminologia "novo terrorismo", ou mesmo por uma inovação no campo da motivação das organizações terroristas.

Não nos resta outro caminho que não concluir por um processo político e retórico de "rotulagem" de um "novo terrorismo" pós-11 de setembro, de forma a permitir a implementação e a consolidação em variados países de um "novo contraterrorismo", que, por óbvio, mostrou-se inadequado na medida em que se valeu de indevidos e arcaicos meios para enfrentar um fenômeno que, conforme já exposto, é milenar.

5 As quatro etapas, denominadas "ondas" temporais e sistemáticas, têm cada qual modus operandi distinto, assim como objetivos e motivações, podendo sobrepor-se umas às outras e ter duração aproximada de algumas décadas (RAPOPORT, 2004). 
A Guerra Global ao Terror deve ser repensada, a começar pela utilização de tal termo, que acaba por conduzir a uma regressão democrática e conspira contra o Estado de Direito. Além de ter fracassado, dispendeu enormes custos e vidas, tolhendo inafastáveis direitos fundamentais. Da mesma forma, acabou por recrudescer e ampliar a resistência e a agressividade de células de organizações terroristas, ocasionando dispersos conflitos, desencadeando a formação de uma segunda geração de líderes terroristas e provocando ainda mais terrorismo.

É urgente operacionalizar uma estratégia preventiva, por meio das instituições policiais e judiciais, em um viés de diminuição da criminalidade. Não mais se pode buscar um enfrentamento ao terrorismo a partir de estratégias belicosas e retributivas, que a história demonstra terem sido, além de inócuas, grandes propulsoras do fenômeno. Parece-nos claro estarmos frente a dois desafios contemporâneos, robustos, sensíveis e inadiáveis.

Um deles, apresentado ao Direito e à Sociedade, é a promoção de uma mudança na visão dominante sobre a natureza do terror e das respostas contraterroristas. O outro, colocado ao Estado, é o enfrentamento ao terrorismo como um ato criminoso, e a operacionalização de suas forças de segurança policiais e do sistema jurídico nacional de forma democrática e transparente.

José Fernando Moraes Chuy

Polícia Federal e Universidade Nova de Lisboa

Doutorando em Direito e Segurança na Universidade Nova de Lisboa. Mestre em Ciências Policiais pelo Instituto Superior de Ciências Policiais e Segurança Interna de Portugal. Docente da Academia Nacional de Polícia (Polícia Federal do

BRASIL).

Delegado de Polícia Federal. 


\section{New Terrorism? The Failure of War to TERror to Virtual Radicalization}

\section{ABSTRACT}

The purpose of this study is to analyse the "new terrorism". It is an expression that became popular after 9/11 through a planned political speech that justified the "Global War on Terror" and that has the rejection of terrorism as a symbol of crime. We will seek to present some outcomes of the exclusive use of military forces in the management of this issue, especially the training of a second generation of terrorist leaders through virtual radicalization.

KEYwORDs: New terrorism. Political speech. Virtual radicalization. Global war.

\section{¿Nuevo Terrorismo? El Fracaso De La Guerra Al Terror a la Radicalización VirTUAL}

\section{RESUMEN}

El propósito de este trabajo es estudiar el "nuevo terrorismo", expresión que, en cierto modo, terminó popularizándose después del 11/9, a través de un discurso político planificado que justificó la "Guerra Global contra el Terrorismo" y que trajo como marca el rechazo del terrorismo como delito. Buscaremos sacar a la luz algunas consecuencias de priorizar el uso de la fuerza militar ante el fenómeno, especialmente la formación de una segunda generación de líderes terroristas a través de la virtual radicalización.

Palabras clave: Nuevo terrorismo. Discurso político. Radicalización virtual. Guerra Mundial.

\section{REFERÊNCIAS BIBLIOGRÁFICAS}

AHMARI, Sohrab. Inside the Mind of the Western Jihadist. Disponível em < https://www.wsj.com/articles/sohrab-ahmariinside-the-mind-of-the-western-jihadist-1409352541 >. Acesso em: 19 ago. 2020. 
ALEXANDER, Jonh B. Vencendo a guerra: armas avançadas, estratégias e conceitos para o mundo pós onze de setembro. Tradução de Joubert de Oliveira Brízida. Rio de Janeiro: Editora Welser-Itage, 2005.

BARRETT, Richard. The Islamic State. The Soufan Group, 2014 Disponível em: http://soufangroup.com/wp-content/ uploads/2014/10/TSG-The-Islamic-State-Nov14.pdf. Acesso em: 29 ago. 2019.

BECK, Glenn. It is About Islam: Exposing the truth about ISIS, Al Qaeda, Iran, and the Caliphate. New York: Threshold Editions/ Mercury Radio Arts, 2015.

BUSH, George W. The National Security Strategy of the United States of America, Washington, DC: The White House, September 2002. Disponível em: https://georgewbush-whitehouse.archives.gov/nsc/ nss/2002/. Acesso em: 22 jan. 2020.

CALLEGARI, André Luís. et al. O crime de Terrorismo: Reflexões críticas e comentários à Lei de Terrorismo: de acordo com a Lei ${ }^{\circ}$ 13.260/2016. Porto Alegre: Livraria do Advogado Editora, 2016, p. 16 e 23 .

CARVALHO, Hernâni. Terroristas: como aderem, como nos olham e como agem entre nós. Matéria Prima, 2016.

COCKBURN, Patrick. A origem do Estado Islâmico: o fracasso da guerra ao terror e a ascensão jihadista. Trad. Antônio Martins. São Paulo: Autonomia Literária, 2015.

CRENSHAW, Marta. A estratégia contraterrorista dos Estados Unidos. In: HERTZ, Mônica; AMARAL, Arthur Bernardes do (orgs.). Terrorismo \& Relações Internacionais: perspectivas e desafios para o século XXI. Rio de Janeiro: PUC-Rio: Edições Loyola, 2010.

CRENSHAW, Martha. O terrorismo visto como um problema de segurança internacional. In: HERTZ, Mônica; AMARAL, Arthur Bernardes do (org). Terrorismo \& Relações Internacionais: perspectivas e desafios para o século XXI. Rio de Janeiro: PUC-Rio: Edições Loyola, 2010.

CRENSHAW, Martha. The Debate over "New" vs. "old Terrorism. In: KARAWAN, I. A.; McCORMACK, W.; REYNOLDS, S. E. 
(edits.). Values and Violence. Studies in Global Justice. v. 4. Springer: Dordrecht, 2008.

DEMANT, Peter Robert. Terrorismo e globalização: extremização religiosa ou leilão midiático? In: HERTZ, Mônica; AMARAL, Arthur Bernardes do (org). Terrorismo \& Relaçôes Internacionais: perspectivas e desafios para o século XXI. Rio de Janeiro: PUC-Rio: Edições Loyola, 2010.

DÍAZ MATEY, Gustavo. El papel de la inteligencia en la lucha contra el terrorismo salafista yihadista. Revista CIDOB d'Afers Internacionals n.116, p. 207-228, set. de 2017.

DUYVESTEYN, Isabelle. How New is the New Terrorism. Studies In Conflict \& Terrorism, v. 27, n. 5, p. 439-454, 2004.

EUA - Estados Unidos da América. Memorando do Secretário de Defesa Donald Rumsfeld. Global War on Terrorism, out. 2003. Disponível em: https://fas.org/irp/news/2003/10/rumsfeld101603. pdf. Acesso em: 22 dez. 2019.

FERNANDES, Luís Miguel Fiães. A insegurança e as políticas públicas de segurança. In: GOUVEIA, Jorge Bacelar (coord.). Estudos de Direito e Segurança. v. II. Coimbra: Almedina, 2012. p. 307-325.

FONSECA, Guilherme Damasceno; LASMAR, Jorge Mascarenhas. Passaporte para o terror: os voluntários do Estado Islâmico. Curitiba: Appris, 2017.

FONSECA, José Nunes da. O conceito de segurança nacional perspectivado para 2030. Boletim Ensino: Investigação, Lisboa, n. 11, p. 81-115, nov. 2011.

FRAGA IRIBARNE, Manuel. El terrorismo hoy. In: MOREIRA, Adriano. Terrorismo. Coordenador Adriano Moreira. 2 ed., Coimbra: Almedina, 2004.

FREITAS DO AMARAL, Diogo. Reflexão sobre alguns aspectos jurídicos do 11 de setembro e suas sequelas. In: RAMOS, Rui Manoel de Moura et al. (com. org.). Estudos em Homenagem à Professora Doutora Isabel de Magalhães Collaço. v. II. Coimbra: Almedina, 2002.p. 765-777. 
FROELICH, Ivani Vassoler. A política externa americana e seus críticos. Revista Brasileira de Politica Internacional, v. 48, n 2, p. 205-215, dez. 2005. Disponível em: http://www.scielo.br/scielo. php?script $=$ sci_arttext\&pid $=$ S0034-73292005000200011\&lng=en

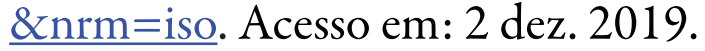

GANOR, Boaz. The Counter-Terrorism Puzzle: a Guide for Decision Makers. New Brunswick, NJ: Transaction, 2005.

GLENNY, Misha. McMáfia: crime sem fronteiras. Trad. Lucia Boldrini. São Paulo: Companhia das Letras, 2008, p. 186-188. GOFAS, Andreas. "Old" vs. "New" Terrorism: What's in a Name? Uluslararası İlişkiler, v. 8, n. 32, p. 17-32, Winter 2012.

GONÇALVES, Joanisval Brito; REIS, Marcus Vinícius. Terrorismo: conhecimento e Combate. Niterói: Impetus, 2017.

GRAY, Colin. Strategy and Politics. Nova Iorque: Routledge,, 2016.

GUEDES, Armando Marques. Ligações perigosas, conectividade, coordenação e aprendizagem em redes terroristas. Coimbra: Almedina, 2007.

HOFFMANN, Florian. Mudança de paradigma? Sobre Direitos Humanos e Segurança Humana no mundo pós-11 de setembro. In: HERTZ, Mônica; AMARAL, Arthur Bernardes do (org.). Terrorismo \& Relações Internacionais: perspectivas e desafios para o século XXI. Rio de Janeiro: PUC-Rio: Edições Loyola, 2010.

JACKSON, Richard. Writing the War on Terrorism: Language, Politics and Counter-Terrorism. Manchester: Manchester University Press, 2005.

JACKSON, Richard. Genealogy, Ideology, and Counter-Terrorism: Writing Wars on Terrorism from Ronald Reagan to George W. Bush Jr. Studies in Language \& Capitalism 1, p. 163-193, 2006.

JANUÁRIO, Rui; GAMEIRO, António. Direito Internacional Público contemporâneo e Relaçôes Internacionais. v. I. Coimbra: Coimbra Editora, 2011.

KAJIBANGA, Rosa. Defesa nacional: novas ameaças. Working Papers Direito, Segurança e Democracia, CEDIS - Faculdade de Direito da Universidade Nova de Lisboa, 2016. Disponível em: 
https://www.academia.edu/35174837/Defesa_Nacional_novas_ amea\%C3\%A7as?auto=download. Acesso em: 10 nov. 2019.

KURTULUS, Ersun N. The "New Terrorism" and its Critics. Studies In Conflict \& Terrorism, v. 34, p. 476-500, 2011.

LAQUEUR, Walter. The New Terrorism: Fanaticism and the Arms of Mass Destruction. Oxford: Oxford University Press, 1999.

MACHADO, Jónatas. Direito Internacional: do paradigma clássico ao pós-11 de setembro. 4. ed. Coimbra: Editora Coimbra, 2013.

MATOS, Hermínio Joaquim de. Requiem para o "Estado Islâmico"? Jihadismo na Europa - Infiltração, Dissimulação e Engano no Planeamento de Ataques Terroristas. In: CHUY, José Fernando Moraes; FAGUNDES, Carlos Frederico Felício; LASMAR, Jorge Mascarenhas (org.). Perspectivas do Terrorismo Transnacional Contemporâneo. Curitiba: Arraes, 2019.

MCCANTS, William. The ISIS Apocalypse: the history, strategy, and doomsday vision of the Islamic State. New York: Picador, 2016.

MURPHY, John M. “Our Mission and Our Moment": George W. Bush and September $11^{\text {th. }}$. Rhetoric \& Public Affairs, v. 6, n. 4, p. 607632, 2003.

NAJI, Abu Bakr. The management of savagery: the most critical stage through which the ummah will pass. Tradução de William McCants. Harvard: John Olin Institute for Strategic Studies at Harvard University, 2006.

NAPOLEONI, Loretta. A Fênix Islamista: o Estado Islâmico e a reconfiguração do Oriente Médio. Tradução Milton Chaves de Almeida, 2 ed., Rio de Janeiro: Bertrand Brasil, 2015.

NYE JR, Joseph S. O futuro do poder. Tradução de Luís Oliveira Santos; revisão de Pedro Ernesto Ferreira. Lisboa: Círculo dos Leitores, 2012.

PARKER, Ian. Discursive resources in the Discourse Unit. Discourse Analysis, v. 1, n. 1, 2003. Disponível em: http://extra.shu.ac.uk/daol/ index.html. Acesso em: 2 dez. 2019.

RAMOS, António Fonte. A Nova Dimensão do Terrorismo Transnacional e o seu Impacto no Sistema Político Internacional - 
do 11 de setembro ao 11 de Março. In: Estratégias de Prevenção e Resposta. Lisboa: IESM, p. 27-37.

RAPOPORT, David C. The Four Waves of Modern Terrorism. Washington: Georgetown University Press, 2004.

SCANDOLARA, Daniel L. G. Estado Islâmico: um fim? Século XXI: Revista de Relaçôes Internacionais, Porto Alegre, v. 8, n. 2, 2017. SILBERSTEIN, Sandra. War of Words: language, politics and 9/11. London/New York: Routledge, 2004.

SILVA, Élzio Vicente da. Operações especiais de Policia Judiciária: e ruptura de planos de ataque terrorista. Barueri: Novo Século Editora, 2017.

STERN, Jessica; BERGER, J.M.. Estado Islâmico, Estado de Terror. Rio Tinto, Vogais, 2015, p.101-115

STEVENSON, Jonathan. Pragmatic Counter-terrorism. Survival, v. 43, n. 4, 2001. Disponível em: http://www.tandfonline.com/doi/ abs/10.1080/00396330112331343115. Acesso em: 22 out. 2019.

SUAREZ, Marcial A. Garcia. As guerras de George W. Bush e o Terrorismo no século XXI. Curitiba: Appris, 2013.

TOMÉ, Luís. "Estado Islâmico": percurso e alcance um ano depois da autoproclamação do "Califado". JANUS.NET e-journal of International Relations, v. 6, n. 1, maio-out. 2015. Acesso em: 2 dez. 2019.

TOMÉ, Luís. Terrorismo vis à vis Desenvolvimento. Entrevista para Trabalho de Investigação do Curso de Estado-Maior Conjunto de José Cerdeira. Lisboa, 18 de mar. 2012.

TORGA, Miguel. Diário: v. XIII-XVI. 5. ed. Alfragide: D. Quixote, 2011.

TUCKER, David. What is New about the New Terrorism and How Dangerous is It? Terrorism and Political Violence. v. 13, n. 3, 2001.

USA - United States of America. Patriot Act, 26 out. 2001. Disponível em: https://epic.org/privacy/terrorism/hr3162.html. Acesso em: 21 jan. 2020. 
UNITED NATIONS OFFICE ON DRUGS AND CRIMES.

The use of the internet for terrorists purposes. Viena: United Nations, 2012. Disponível em: <http://www.unodc.org/ documents/frontpage/

Use_of_Internet_for_Terrorist_Purposes.pdf.>. Acesso em: 21ago. 2017.

VIOLA, Renato. Globalização, democracias de mercado, radicalismo islâmico e terrorismo. In: HERTZ, Mônica; AMARAL, Arthur Bernardes do (org.). Terrorismo \& Relações Internacionais: perspectivas e desafios para o século XXI. Rio de Janeiro: PUC-Rio Edições Loyola, 2010.

WEISS, Michael; HASSAN, Hassan. ISIS Inside the Army of Terror. New York: Regan Arts, 2015. 